\title{
Free Testosterone Measurement
}

National Cancer Institute

\section{Source}

National Cancer Institute. Free Testosterone Measurement. NCI Thesaurus. Code C74785.

The determination of the amount of free testosterone present in a sample. 